\title{
Sistem Pendukung Keputusan Kenaikan Jabatan Menggunakan Metode Algoritma Nä̈ve Bayes Classifier
}

\author{
P S Dewi*1, C K Sastradipraja ${ }^{2}$, D Gustian ${ }^{3}$ \\ Program Studi Sistem Informasi, Universitas Nusa Putra ${ }^{123}$ \\ J1. Raya Cibolang No. 21, Cisaat Kabupaten Sukabumi, 43152, Jawa Barat, Indonesia ${ }^{123}$ \\ Putrisukmadewi97@gmail.com*1, cecep.kurnia@nusaputra.ac.id ${ }^{2}$,gustiandudih@nusaputra.ac.id ${ }^{3}$ \\ diterima: 9 September 2020 \\ direvisi: 25 Februari 2021 \\ dipublikasi: 1 Maret 2021
}

\begin{abstract}
Abstrak
Penelitian ini bertujuan untuk membangun sebuah sistem informasi yang dapat menunjang perusahaan dalam pengambilan keputusan khususnya tentang promosi jabatan pada PT. Busana Indah Global. Hal ini dilatar belakangi oleh sulitnya menentukan layak tidaknya seorang karyawan yang telah dipromosikan untuk naik jabatan, dikarenakan sistem yang belum terkomputerisasi dan dokumen data karyawan yang bertumpuk. Pada penelitian ini, data yang digunakan adalah data kenaikan jabatan karyawan di PT. Busana Indah Global dan metode yang digunakan adalah metode algoritma Nä̈ve Bayes Classifier. Dan untuk mengetahui seberapa baik algoritma Nä̈ve Bayes Classifier digunakan pada penelitian ini, maka digunakan software RapidMiner untuk melakukan pengujian. Dari pengujian di RapidMiner menghasilkan nilai akurasi sebesar 91,67\% dan nilai ROC sebesar 0,979 yang artinya algoritma Nä̈ve Bayes Classifier sangat baik digunakan pada penelitian ini. Setelah melakukan pengujian menggunakan software RapidMiner dan mendapatkan hasil pengujian, kemudian diimplementasikan ke dalam sebuah sistem menggunakan PHP dan MySQL yang dirancang untuk melakukan prediksi kenaikan jabatan. Hasil prediksi yang didapatkan dari sistem sudah sesuai dengan hasil perhitungan yang didapatkan dari software RapidMiner dan perhitungan manual. Berdasarkan penelitian yang telah dilakukan bahwa sistem pendukung keputusan yang dibangun ini dapat diaplikasikan pada PT. Busana Indah Global (BIG) sehingga mampu mempermudah dalam menentukan kelayakan kenaikan jabatan bagi karyawannya.
\end{abstract}

Kata kunci: Keputusan; Jabatan; Algoritma; Nä̈ve Bayes Classifier

\begin{abstract}
This research aims to build an information system that can support the company in decision-making, especially about the promotion of positions at PT. Global Beautiful Fashion. This is motivated by the difficulty of determining whether or not an employee has been promoted to office, due to an uncomputed system and stacked employee data documents. In this study, the data used is data on the promotion of employee positions at PT. Global Beautiful Clothing and the method used is the Naïve Bayes Classifier algorithm method. And to find out how well the Nä̈ve Bayes Classifier algorithm was used in this study, RapidMiner software was used to conduct testing. RapidMiner's testing yielded an accuracy score of $91.67 \%$ and a ROC value of 0.979 which means the Nä̈ve Bayes Classifier algorithm was very well used in this study. After testing using RapidMiner software and obtaining test results, it is then implemented into a system using PHP and MySQL designed to predict promotion. The prediction results obtained from the system are following the calculation results obtained from RapidMiner software and manual calculations. Based on the research that has been done that the decision support system built can be applied to PT. Busana Indah Global (BIG) to make it easier to determine the feasibility of promotion for its employees.
\end{abstract}

Keywords: Decision; Position; Algorithm; Nä̈ve Bayes Classifier

\section{Pendahuluan}

Di zaman sekarang ini seiring dengan perkembangan teknologi yang sudah semakin canggih dan globalisasi yang semakin berkembang pesat, membuat sumber daya manusia 
(SDM) dituntut untuk terus meningkatkan skill dan kemampuan yang dimiliki supaya mereka mampu menghadapi persaingan. Pada dasarnya, SDM adalah faktor penentu keberhasilan kerja di suatu perusahaan. Sumber daya manusia dalam suatu organisasi perusahaan merupakan hal yang sangat penting untuk mendukung kemajuan dan kualitas perusahaan dalam mencapai tujuan [1]. Salah satu proses penting yang sering terjadi di perusahaan adalah promosi kenaikan jabatan karyawan. Biasanya promosi kenaikan jabatan ini direkomendasikan oleh atasan atau pihak tertentu berdasarkan faktor kualitas kerja, masa kerja, perilaku dan absensi karyawan yang bersangkutan. Kenaikan jabatan merupakan suatu faktor yang sangat penting untuk meremajakan suatu posisi jabatan agar diduduki oleh seseorang yang mempunyai kriteria-kriteria yang cocok untuk menempati suatu jabatan yang diusulkan [1].

PT. Busana Indah Global (BIG) adalah perusahaan yang bergerak dibidang industri pakaian. Setiap ada kekosongan jabatan perusahaan selalu mengadakan promosi kenaikan jabatan karyawan untuk mengisi kekosongan tersebut dan juga sebagai salah satu bentuk apresiasi perusahaan kepada karyawannya atas kinerja mereka. Akibatnya, karyawan merasa dituntut untuk semakin meningkatkan kualitas kerja mereka agar bisa dipromosikan oleh pihak yang bersangkutan. Tapi tentunya perusahaan memiliki prosedur dan kriteria tertentu untuk memilih karyawan yang layak untuk naik jabatan, tidak hanya berdasarkan kualitas kerja saja. Namun permasalahan timbul ketika persaingan karyawan yang semakin ketat justru membuat pihak perusahaan sulit untuk menentukan apakah karyawan yang telah dipromosikan untuk naik jabatan tersebut layak atau tidak, karena terkadang pihak-pihak yang bersangkutan untuk mempromosikan karyawan dan pihak HRD tidak mengikuti prosedur yang sudah ada.

Di sisi lain, perusahaan juga memiliki data-data tentang kenaikan jabatan karyawan yang bertumpuk, namun perusahan masih belum mampu mengelola data tersebut secara optimal. Bahkan pihak perusahaan itu sendiri belum menyadari bahwa tumpukan data-data tersebut bisa dijadikan sebuah informasi yang berguna. Untuk membantu mengelola data-data tersebut dan menemukan informasi yang berguna, maka dilakukan menggunakan teknik data mining. Karena data mining merupakan sebuah teknologi baru yang sangat berguna bagi perusahaan untuk menemukan informasi yang sangat penting dan berguna untuk mendukung pengambilan keputusan penting [2]. Data mining adalah sebuah proses pencarian secara otomatis informasi yang berguna dalam tempat penyimpanan data berukuran besar. Salah satu fungsi data mining adalah memprediksi sebuah data berdasarkan data yang sudah ada sebelumnya [3]. Adapun manfaat penggunaan teknik data mining tersebut, diantaranya dapat mempermudah pihak perusahaan dalam menentukan layak atau tidaknya karyawan tersebut untuk naik jabatan berdasarkan data-data yang sudah ada sebelumnya. Untuk lebih mempermudah lagi, maka digunakan metode klasifikasi data mining. Karena teknik ini dapat memberikan klasifikasi pada data baru dengan memanipulasi data yang ada yang telah diklasifikasi dengan menggunakan hasilnya untuk memberikan sejumlah aturan [3]. Metode klasifikasi yang digunakan yakni Nä̈ve Bayes Classifier. Metode ini merupakan metode klasifikasi yang berdasarkan pada Teorema Bayes, dimana metode ini memanfaatkan perhitungan probabilitas dan statistika yang dapat digunakan untuk memprediksi peluang di masa depan berdasarkan pengalaman yang terjadi di masa sebelumnya [3]. Nä̈ve Bayes Classifier terbukti memiliki akurasi dan kecepatan yang tinggi saat diaplikasikan ke dalam database dengan data yang besar [4]. Nä̈ve Bayes Classifier juga memiliki kinerja yang sangat baik dalam menangani data di kehidupan nyata dan dapat mengambil keputusan dengan sangat baik, sebagai pertimbangan yaitu pada penelitian Perbandingan Klasifikasi Tugas Akhir Mahasiswa Jurusan Teknik Informatika Menggunakan Metode Nä̈ve Bayes Classifier dan K-Nearest Neighbor. Diketahui bahwa hasil akurasi Nä̈ve Bayes Classifier 
lebih baik dibandingkan dengan k-Nearest Neighbor yakni sebesar 87\% [5]. Maka dari itu penulis akan mencoba kembali menggunakan metode Nä̈ve Bayes Classifier untuk pengambilan keputusan layak atau tidaknya seorang karyawan yang telah dipromosikan untuk naik jabatan.

\subsection{Penelitian Terkait}

\section{Kajian Pustaka}

Penelitian terkait pertama diperoleh dari jurnal Penerapan Algoritma Klasifikasi Naive Bayes Untuk Data Status Huni Rumah Bantuan Dana Rehabilitasi Dan Rekonstruksi Pasca Bencana Erupsi Gunung Merapi 2010 yang diteliti oleh Nurhadi Wijaya. Penelitian ini menyimpulkan bahwa algoritma klasifikasi Naive Bayes dapat diterapkan untuk melakukan klasifikasi data status huni bantuan dana rumah rehab rekon pasca bencana erupsi Merapi 2010 dengan hasil akurasi klasifikasi mencapai nilai sebesar 89,59\%. Hasil performa akurasi klasifikasi diperoleh nilai AUC (Area Under the ROC curve) sebesar 0,826, maka Algoritma Naive Bayes dapat diterapkan untuk mengklasifikasi data status huni hunian rumah bantuan dana rumah (BDR) rehab rekon pasca erupsi Merapi 2010 dengan kategori baik [6].

Penelitian terkait kedua diperoleh dari jurnal Implementasi Data Mining Dengan Algoritma Nä̈ve Bayes Pada Penjualan Obat yang diteliti oleh Herry Derajad Wijaya dan Saruni Dwiasnati. Penelitian ini menyimpulkan bahwa Pengujian pada data rekapitulasi penjualan obat dengan proses mining Algoritma Nä̈ve Bayes menghasilkan tingkat accuracy dengan nilai $88,00 \%$, dimana dalam pengujian model data, keseluruhan dataset digunakan sebagai data testing. Penelitian ini dilakukan menggunakan tools Rapidminner pada dataset penjualan obat dengan menggunakan algoritma Nä̈ve Bayes [7].

Penelitian terkait kedua diperoleh dari jurnal implementasi algoritma Nä̈ve Bayes pada dataset hepatitis menggunakan RapidMiner yang diteliti oleh Deny Novianti. Penelitian ini menyimpulkan bahwa Metode Naive Bayes termasuk algoritma yang akurat untuk memprediksi karena hasil akurasi menggunakan RapidMiner menunjukkan lebih dari 50\% yaitu sebesar 76,77\% [8].

\subsection{Sistem Pendukung Keputusan}

Sistem Pendukung Keputusan adalah suatu informasi yang spesifik guna membantu manajemen dalam mengambil keputusan, dengan persoalan yang bersifat semi terstruktur secara efektif dan efisien, namun tidak menggantikan fungsi pengambilan keputusan dalam membuat keputusan [9].

Menurut Kusrini (2007), tujuan dari sistem pendukung keputusan adalah:

a. Membantu manajer dalam pengambilan keputusan atas masalah semistruktur

b. Memberikan dukungan atas pertimbangan manajer dan bukannya dimaksudkan untuk menggantikan fungsi manajer

c. Peningkatan produkivitas

d. Berdaya saing

\subsection{Data Mining}

Gartner Group, data mining adalah proses menemukan hubungan baru yang mempunyai arti, pola dan kebiasaan dengan memilah-milah sebagian besar data yang dismpan dalam media penyimpanan dengan menggunakan teknologi pengenalan pola seperti teknik statisik dan matematika. Data mining merupakan gabungan dari beberapa disiplin ilmu yang menyatuan teknik dari pembelajaran mesin, pengenalan poa, statistik, database dan visualisasi untuk penanganan permasalahan pengambilan informasi dari database besar [10]. 
Sebagai suatu rangkaian proses, tahap-tahap dalam Data Mining menurut Saleh (2015) adalah sebagai berikut [11].

a. Pembersihan data (Data Cleaning)

Pembersihan data merupakan proses menghilangkan noise dan data yang tidak konsisten atau data tidak relevan.

b. Integrasi data (Data Integration)

Integrasi data merupakan penggabungan data dari berbagai database ke dalam satu database baru.

c. Seleksi data (Data Selection)

Data yang ada pada database terkadang tidak semuanya dipakai, oleh karena itu hanya data yang sesuai untuk dianalisis yang akan diambil dari database.

d. Transformasi data (Data Transformation)

Data diubah atau digabung ke dalam satu database yang sesuai untuk diproses dalam data mining.

e. Proses Mining

Merupakan suatu proses utama saat metode diterapkan untuk menemukan pengetahuan berharga dan tersembunyi dari data.

f. Evaluasi pola (Pattern Evaluation)

Untuk mengidentifikasi pola-pola menari ke dalam knowledge based yang ditemukan.

g. Presentasi pengetahuan (Knowledge Presentation)

Merupakan visualisasi dan penyajian pengetahuan mengenai metode yang digunakan.

\subsection{Metode Klasifikasi}

Menurut Prasetyo, klasifikasi merupakan suatu pekerjaan menilai objek data untuk memasukannya ke dalam kelas tertentu dari sejumlah kelas yang tersedia. Dalam klasifikasi ada dua pekerjaan utama yang dilakukan, yaitu pembangunan model sebagai prototipe untuk disimpan sebagai memori dan penggunaan model tersebut untuk melakukan pengenalan/klasifikasi/prediksi pada suatu objek data lain agar diketahui di kelas mana objek data tersebut dalam model yang sudah disimpannya [11].

Algoritma klasifikasi yang banyak digunakan secara luas, yaitu Decision/classification trees, Bayesian classifiers/ Nä̈ve Bayes classifiers, Neural networks, Analisa Statistik, Algoritma Genetika, Rough sets, k-nearest neighbor, Metode Rule Based, Memory based reasoning, dan Support vector machines (SVM) [4].

\subsection{Metode Nä̈ve Bayes Classifier}

Merupakan salah satu algoritma pemecahan masalah yang termasuk ke dalam metode klasifikasi pada data mining. Nä̈ve Bayes Classifier mengadopsi ilmu statistika yaitu dengan menggunakan teori kemungkinan (probabilitas) untuk menyelesaikan sebuah kasus Supervised Learning, artinya dalam himpunan data terdapat label, class atau target sebagai acuan atau gurunya.

Naïve Bayes Classifier dalam konsep penyelesaiannya tidak jauh beda dengan konsep KNearest Neighbor. Seperti kita ketahui bahwasannya dalam metode klasifikasi terdapat beberapa fase penyelesaian yaitu dimulai dari training dan diakhiri dengan proses testing sehingga dihasilkan sebuah keputusan yang akurat.

Persamaan Teorema Bayes

$$
\mathrm{P}(\mathrm{H} \mid \mathrm{X})=\frac{\mathrm{P}(\mathrm{X} \mid \mathrm{H}) \mathrm{P}(\mathrm{H})}{\mathrm{P}(\mathrm{X})}
$$

Keterangan:

$\mathrm{X}$ : sampel data yang memiliki kelas (label) yang tidak diketahui 
$\mathrm{H}$ : hipotesa bahwa $\mathrm{X}$ adalah data kelas label

$\mathrm{P}(\mathrm{H})$ : peluang dari hipotesa $\mathrm{H}$

$\mathrm{P}(\mathrm{X})$ : peluang dari data sampel yang diamati

$\mathrm{P}(\mathrm{X} \mid \mathrm{H})$ : peluang dari data sampel $\mathrm{X}$ bila diasumsikan bahwa hipotesa benar

Sehingga Nä̈ve Bayes Classifier dapat didefinisikan juga sebagai metode klasifikasi yang berdasarkan teori probabilitas dan teorema bayesian dengan asumsi bahwa setiap variabel atau parameter penentu keputusan bersifat bebas (independence) sehingga keberadaan setiap variabel tidak ada kaitannya dengan atribut yang lain [3].

\subsection{Probabilitas}

Probabilitas merupakan besarnya kesempatan (kemungkinan) suatu peristiwa akan terjadi. Berdasarkan pengertian probabilitas tersebut terdapat beberapa hal yang penting, yaitu besarnya kesempatan dan peristiwa akan terjadi. Semakin kecil probabilitas suatu peristiwa, semakin kecil kesempatan peristiwa tersebut akan terjadi. Sebaliknya semakin besar probabilitas suatu peristiwa, semakin besar kesempatan peristiwa tersebut akan terjadi [12].

\subsection{RapidMiner}

Rapidminer merupakan salah satu software data mining pengolahan data set untuk mencari pola data sesuai dengan tujuan dari pengolahan data tersebut, tidak semua algoritma yang ada dapat sesuai atau dapat mengolah data set yang ada, harus dilakukan penyesuaian pola data dan sesuai dengan tujuan dari pengolahan data tersebut [13].

\subsection{Tahapan Penelitian}

\section{Metode Penelitian}

\subsubsection{Tahap Pengumpulan Data}

Pada tahap ini dilakukan pengumpulan data tentang teori-teori yang berhubungan dengan metode Nä̈ve Bayes Classifier, data karyawan di perusahaan, cara perhitungan algoritma Nä̈ve Bayes Classifier. Semua proses pengumpulan data diperoleh dari studi pustaka, wawancara, dan observasi, yang dijelaskan sebagai berikut:

\section{Studi Pustaka}

Tahapan studi pustaka dilakukan untuk mengumpulkan data atau informasi yang relevan dengan penelitian ini. Seperti pengumpulan informasi dari buku, internet, dan lainnya. Studi pustaka diperlukan untuk memilih data yang berkaitan dengan penelitian seperti metode Naive Bayes Classifier.

2. Wawancara

Tahapan wawancara ini adalah pengumpulan data melalui proses wawancara dengan mengajukan pertanyaan-pertanyaan kepada pihak perusahaan yang bersangkutan. Pertanyaan yang diajukan adalah pertanyaan yang bersifat fleksibel untuk mengetahui mekanisme pemilihan karyawan yang layak untuk naik jabatan.

3. Observasi

Tahapan observasi ini adalah pengumpulan data melalui proses pengamatan objek secara langsung, agar bisa mengetahui alur kerja yang terjadi pada objek yang akan diteliti.

\subsubsection{Tahap Pengolahan Data}

1. Seleksi Data

Pada tahap ini dilakukan penyeleksian data yang akan digunakan pada proses data mining dan disimpan di dalam suatu berkas, terpisah dari basis data operasional.

2. Pemilihan Data 
Yang dilakukan pada tahap ini adalah dengan membuang duplikasi data dan menghilangkan beberapa atribut yang tidak dipakai. Pada data karyawan ini ada 9 atribut dan tidak semua atribut tersebut digunakan untuk memprediksi kenaikan jabatan karyawan. Dari 9 atribut, hanya 7 atribut yang dipakai dan 2 atribut yang dihapus adalah alamat dan bagian.

3. Transformasi Data

Yang dilakukan pada tahap ini adalah mentransformasikan bentuk data yang belum jelas ke dalam bentuk data yang valid dan siap untuk dilakukan proses data mining.

4. Data Mining

Pada tahap ini, yang dilakukan adalah melakukan perhitungan data mining dengan menggunakan metode Nä̈ve Bayes Classifier untuk menghasilkan nilai akurasi data.

5. Interpretasi

Pada tahap ini dilakukan proses pembentukan hasil keluaran prediksi kenaikan jabatan karyawan.

\subsubsection{Peracangan Algoritma}

1. Menentukan data karyawan.

2. Menghitung probabilitas perkelas

3. Menghitung probabilitas data latih dengan mengalikan semua probabilitas perkelas di data latih.

4. Bandingkan probabilitas akhir, lalu pilih probabilitas yang nilainya paling tinggi.

5. Selesai

\subsection{Desain Sistem}

\subsubsection{Use Case Diagram}

Use Case Diagram adalah suatu model yang bertujuan menjelaskan alur atau proses sistem yang dibuat dengan menggunakan simbol. Use Case Diagram prediksi kenaikan jabatan karyawan ini menjelaskan tentang alur interaksi sistem yang akan dibangun untuk memprediksi kenaikan jabatan karyawan. Use Case Diagram ini mencakup semua sistem dari mulai aktor dan interasksi Use Case nya. Berikut adalah Use Case Diagram prediksi kenaikan jabatan karyawan sebagaimana dapat dilihat pada gambar 1 di bawah ini.

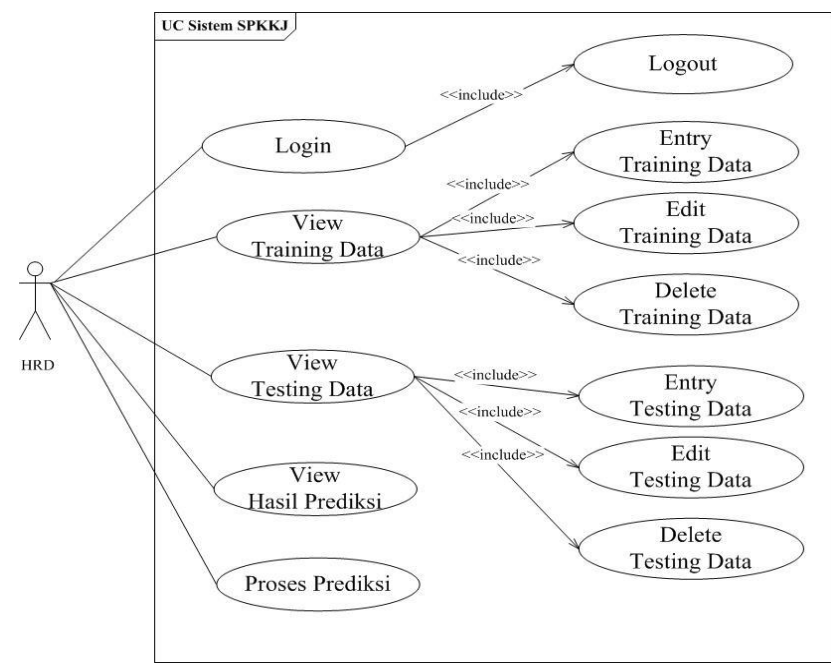

Gambar 1. Use Case Diagram Prediksi Kenaikan Jabatan Karyawan

Pada tabel 1 di bawah ini merupakan penjelasan dari use case diagram disertai dengan aktivitas dari setiap aktornya. 
Tabel 1. Deskripsi Use Case

\begin{tabular}{|l|l|l|}
\hline No & \multicolumn{1}{|c|}{ Use Case } & \multicolumn{1}{c|}{ Aktivitas } \\
\hline 1 & Login & $\begin{array}{l}\text { Melakukan login ke sistem yang menampilkan halaman } \\
\text { utama sistem. }\end{array}$ \\
\hline 2 & Melihat Data Training & $\begin{array}{l}\text { Melihat Data Training, menambah Data Training, } \\
\text { mengubah Data Training dan menghapus Data Training. }\end{array}$ \\
\hline 3 & Melihat Data Testing & $\begin{array}{l}\text { Melihat data testing, menambah data testing, mengubah } \\
\text { data testing dan menghapus data testing. }\end{array}$ \\
\hline 4 & Melihat Hasil Prediksi & Melihat hasil prediksi dari data testing yang diinput. \\
\hline 5 & Menguji Data Testing & $\begin{array}{l}\text { Menginput data testing dan diuji menggunakan metode } \\
\text { algoritma Naüve Bayes Classifier. }\end{array}$ \\
\hline 6 & Log Out & Keluar dari sistem. \\
\hline
\end{tabular}

\subsubsection{Class Diagram}

Class Diagram menggambarkan beberapa class yang terdapat di dalam sistem pendukung keputusan kenaikan jabatan karyawan yang saling berhubungan. Berikut ini adalah Class Diagram sistem pendukung keputusan kenaikan jabatan karyawan sebagaimana tertuang pada gambar 2 berikut ini.

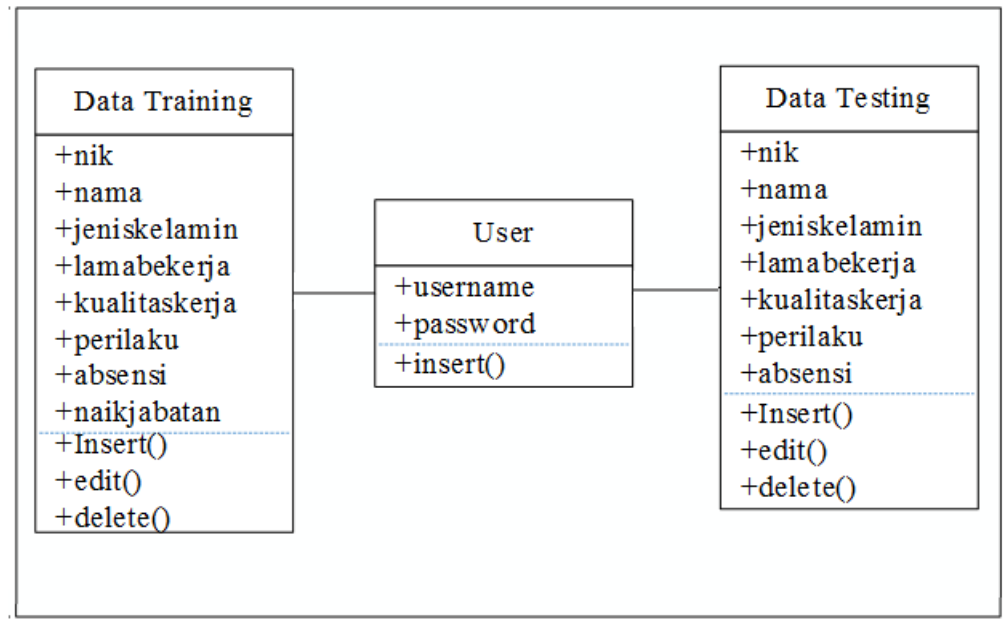

Gambar 2. Class Diagram Prediksi Kenaikan Jabatan Karyawan

\subsubsection{Activity Diagram}

Activity Diagram adalah penjelasan dan deskripsi beberapa alur kegiatan sistem yang sedang didesain, bagaimana alur dari masing-masing dimulai, sebuah keputusan bisa terjadi, serta seperti apa mereka berakhir. Pada gambar 3 di bawah ini merupakan activity diagram prediksi sistem pendukung keputusan kenaikan jabatan karyawan. 


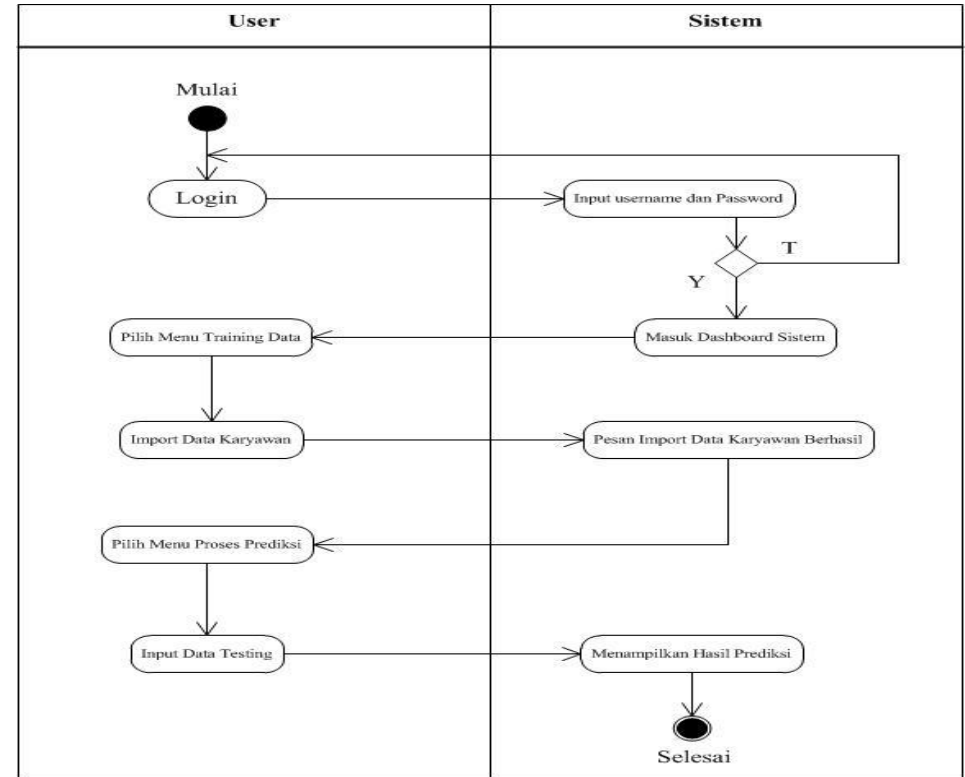

Gambar 3. Activity Diagram Prediksi Kenaikan Jabatan Karyawan

\subsection{Data Penelitian}

\section{Hasil dan Pembahasan}

Pada penelitian ini data penelitian diklasifikasikan ke dalam 2 bagian yaitu, Data Training dan data testing, dimana pada Data Training yang digunakan adalah sebanyak 84 data dan data testing sebanyak 24 data. Klasifikasi data sudah melalui proses data mining menggunakan aplikasi RapidMiner.

\subsection{Perhitungan Nä̈ve Bayes Classifier}

Proses dalam pengolahan data ini menggunakan algoritma Nä̈ve Bayes Classifier yang bertujuan untuk mengetahui hasil dari data yang diteliti dalam membantu perusahaan untuk memprediksi kenaikan jabatan karyawan. Data Training merupakan data yang sudah ada sebelumnya berdasarkan fakta yang sudah terjadi dan digunakan untuk proses learning dalam Nä̈ve Bayes Classifier. Sedangkan data testing adalah data yang akan diuji pada proses pengujian. Adapun kriteria yang dibutuhkan pada proses perhitungan Nä̈ve Bayes Classifier tersaji pada tabel 2 berikut.

Tabel 2. Kriteria Karyawan

\begin{tabular}{|l|l|l|}
\hline No & Kriteria & Kategori \\
\hline 1 & \multirow{2}{*}{ Kualitas Kerja } & Baik \\
\cline { 3 - 3 } & & Kurang Baik \\
\hline 2 & Masa Kerja (Tahun) & $<3$ \\
\cline { 3 - 3 } & & $>=3$ \\
\hline 3 & Perilaku & Baik \\
\cline { 3 - 3 } & & Kurang Baik \\
\hline 4 & Absensi (Perbulan) & $<3$ \\
\cline { 3 - 3 } & & $>=3$ \\
\hline
\end{tabular}

Berikut ini merupakan beberapa sampel dari Data Training sebagaimana tersajikan pada gambar 4 di bawah ini: 


\begin{tabular}{|c|c|c|c|c|c|c|c|}
\hline NIK & Nama & Jenis Kelamin & Lama Bekerja (tahun) & Kualitas Kerja & Perilaku & Absensi & Naik Jabatan \\
\hline BIG-06189 & Wiwin Yullianti & Perempuan & $<3$ & Baik & Baik & $<3$ & Ya \\
\hline BIG-04414 & Sumirah & Perempuan & $<3$ & Baik & Baik & $<3$ & Ya \\
\hline BIG-03829 & Andri Sunandar & Laki-laki & $<3$ & Baik & Baik & $<3$ & Ya \\
\hline BIG-03834 & Indra Permana & Laki-laki & $<3$ & Baik & Baik & $>=3$ & Tidak \\
\hline BIG-04220 & Sumarni Rahmawati & Perempuan & $<3$ & Baik & Baik & $<3$ & $\mathrm{Ya}$ \\
\hline BIG-04527 & Ratna Juwita & Perempuan & $>=3$ & Kurang Baik & Baik & $>=3$ & Tidak \\
\hline BIG-11414 & Rina Rismawati & Perempuan & $>=3$ & Kurang Baik & Kurang Baik & $<3$ & Tidak \\
\hline BIG-17511 & Muhartini & Perempuan & $<3$ & Baik & Baik & $<3$ & Ya \\
\hline BIG-17742 & Esih & Perempuan & $<3$ & Baik & Baik & $<3$ & Ya \\
\hline BIG-18463 & Olis Pertiwi & Perempuan & $<3$ & Baik & Kurang Baik & $<3$ & Tidak \\
\hline BIG-18591 & Risna Purnamasari & Perempuan & $>=3$ & Kurang Baik & Kurang Baik & $>=3$ & Tidak \\
\hline BIG-19134 & Iis Syamsiah & Perempuan & $>=3$ & Kurang Baik & Baik & $>=3$ & Tidak \\
\hline BIG-19770 & Silvi Lisnawati & Perempuan & $>=3$ & Baik & Kurang Baik & $<3$ & Ya \\
\hline BIG-20292 & Miawati & Perempuan & $>=3$ & Baik & Kurang Baik & $<3$ & Ya \\
\hline BIG-20651 & Parid & Laki-laki & $<3$ & Baik & Baik & $<3$ & Ya \\
\hline BIG-21984 & Dede & Laki-laki & $>=3$ & Baik & Kurang Baik & $<3$ & Ya \\
\hline BIG-20649 & Andri Sunandar & Laki-laki & $>=3$ & Baik & Baik & $<3$ & $\mathrm{Ya}$ \\
\hline BIG-17144 & Sumarni Rahmawati & Perempuan & $>=3$ & Kurang Baik & Baik & $<3$ & Ya \\
\hline BIG-17905 & Wiwi Winarti & Perempuan & $>=3$ & Baik & Baik & $<3$ & Ya \\
\hline BIG-20628 & hajar Sari Hastuti & Perempuan & $>=3$ & Baik & Kurang Baik & $>=3$ & Tidak \\
\hline
\end{tabular}

Gambar 4. Sampel Data

Misal ingin diketahui status kenaikan jabatan seorang karyawan dengan lama bekerja kurang dari 3 tahun, kualitas kerja yang baik, perilaku yang baik dan absensi kurang dari 3 .

(a) Menghitung nilai probabilitas kelas

$\mathrm{P}(\mathrm{Ya})=\Sigma$ Ya $/$ Jumlah Total $=54 / 84=0,690$

$\mathrm{P}($ Tidak $)=\Sigma$ Tidak $/$ Jumlah Total $=26 / 84=0,309$

(b) Menghitung nilai probabilitas atribut pada data testing untuk kelas "Ya"

$\mathrm{P}($ Lama Bekerja " $<3$ " $\mid$ Ya $)=14 / 58=0,241$

$\mathrm{P}($ Kualitas kerja "Baik" $\mid \mathrm{Ya})=52 / 58=0,896$

$\mathrm{P}$ (Perilaku "Baik" $\mid$ Ya $)=55 / 58=0,948$

$\mathrm{P}($ Absensi " $<3$ " $\mid$ Ya $)=40 / 58=0,689$

(c) Menghitung nilai probabilitas atribut pada data testing untuk kelas "Tidak"

$P($ Lama Bekerja " $<3$ " $\mid$ Tidak $)=6 / 26=0,230$

$\mathrm{P}$ (Kualitas kerja "Baik" | Tidak $)=7 / 26=0,269$

$\mathrm{P}$ (Perilaku "Baik" | Tidak $)=11 / 26=0,423$

$\mathrm{P}($ Absensi " $<3$ " $\mid$ Tidak $)=10 / 26=0,384$

(d) Menghitung nilai probabilitas akhir

$\mathrm{P}$ (Lama Bekerja "<3" | Ya) * P (Kualitas kerja "Baik" | Ya) * P (Perilaku "Baik" | Ya)

* $\mathrm{P}($ Absensi “<3" $\mid \mathrm{Ya}) * \mathrm{P}(\mathrm{Ya})$

$=0,241 * 0,896 * 0,948 * 0,689 * 0,690$

$=0,108$

$\mathrm{P}$ (Lama Bekerja " $<3$ "| Tidak) * $\mathrm{P}$ (Kualitas kerja "Baik" | Tidak) * $\mathrm{P}$ (Perilaku "Baik" | Tidak) * P (Absensi “<3" | Tidak) * $\mathrm{P}$ (Tidak)

$=0,230 * 0,269 * 0,423 * 0,384 * 0,309$

$=0,003$

Karena $\mathrm{P}(\mathrm{X} \mid \mathrm{Cya}>\mathrm{P}(\mathrm{X} \mid$ Ctidak) maka seorang karyawan dengan lama bekerja kurang dari 3 tahun, kualitas kerja yang baik, perilaku yang baik dan absensi kurang dari 3 diprediksi naik jabatan.

\subsection{Pengujian Data}


Untuk mengetahui seberapa baik metode Nä̈ve Bayes Classifier digunakan pada penelitian ini, maka digunakan software RapidMiner untuk melakukan pengujian. Pengujian dilakukan dengan menggunakan Data Training yang berjumlah 84 data dan data testing 24 sampel data.

\section{a. Nä̈ve Bayes Classifier}

Proses pengujian data rapidminer terdapat pada gambar 5 di bawah ini berikut dengan penjelasannya.

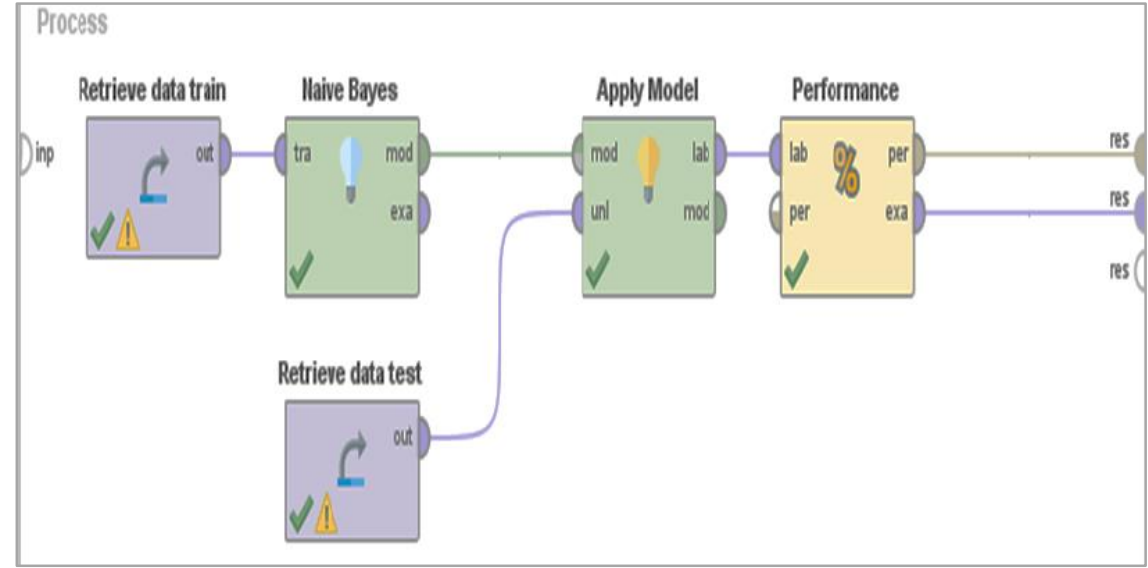

Gambar 5. Proses Pengujian Nä̈ve Bayes Classifier

Pada gambar diatas menunjukan bahwa proses pengujian ditambahkan operator apply model dan performance. Operator apply model digunakan untuk menerapkan model pada data testing yang telah dilatih sebelumnya meggunakan Data Training. Operator apply model bertujuan untuk mendapatkan prediksi pada data testing dan hasil dari apply model diteruskan ke operator performance untuk dilakukan pengujian tingkat akurasinya. Setelah proses pengujian data testing selesai, keluarlah hasil akurasi data seperti pada gambar 6 di bawah ini.

\begin{tabular}{|c|c|c|c|}
\hline \multicolumn{4}{|c|}{ accuracy: $91.67 \%$} \\
\hline & true Ya & true Tidak & class precision \\
\hline pred. Ya & 13 & 2 & $86.67 \%$ \\
\hline pred. Tidak & 0 & 9 & $100.00 \%$ \\
\hline class recall & $100.00 \%$ & $81.82 \%$ & \\
\hline
\end{tabular}

Gambar 6. Hasil Akurasi Pengujian Nä̈ve Bayes Classifier

Pada gambar diatas, tercatat bahwa hasil akurasi Naïve Bayes Classifier dari data testing yakni $91,67 \%$ dengan presentasi class recall ya $100 \%$ dan tidak $81,82 \%$ dengan nilai masingmasing class precission ya $86,67 \%$ dan tidak $100 \%$.

\section{b. Kurva ROC}

Setelah dilakukan proses data testing dan melihat hasil akurasi data testing, dilanjutkan dengan melihat kurva ROC sebagaimana ditampilkan pada gambar 7 di bawah ini. 
Performance keakurasian AUC menurut Gorunescu: 2010 dapat diaplikasikan menjadi lima kelompok yaitu:

- $0,90-1,00=$ Exellent Classification / Unggul

- $0,80-0,90=$ Good Classification / Baik

- $0,70-0,80=$ Fair Classification / Cukup

- $0,60-0,70=$ Poor Classification / Kurang

- $0,50-0,60=$ Failure Classification / Gagal

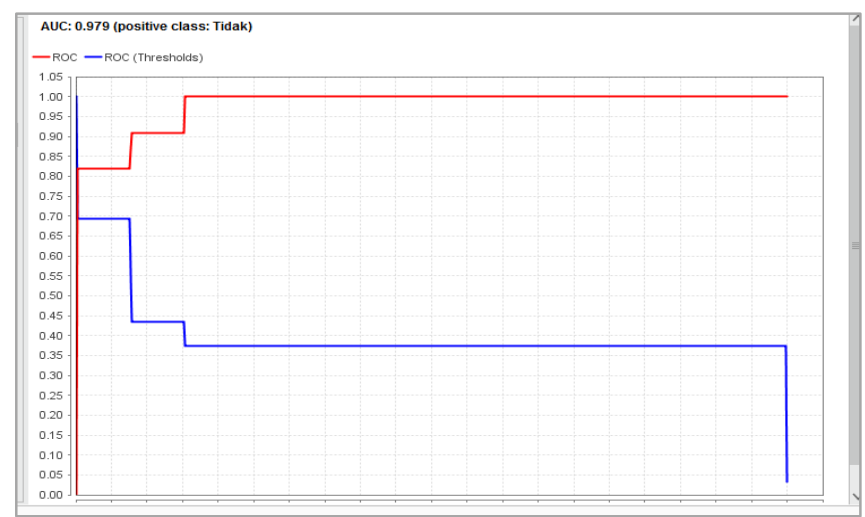

Gambar 7. Kurva ROC

Nampak bahwa Kurva ROC dari perhitungan Naïve Bayes Classifier menggunakan data testing sekitar 0,979, hal ini dapat dikatakan kategori Excellent Classification.

\subsection{Implementasi Sistem}

a. Login Sistem SPKKJ

Tampilan login seperti pada gambar 8 di bawah ini merupakan sistem yang dibangun hanya terdapat satu level yaitu untuk admin saja. Untuk dapat login harus memasukkan username dan password terlebih dahulu.

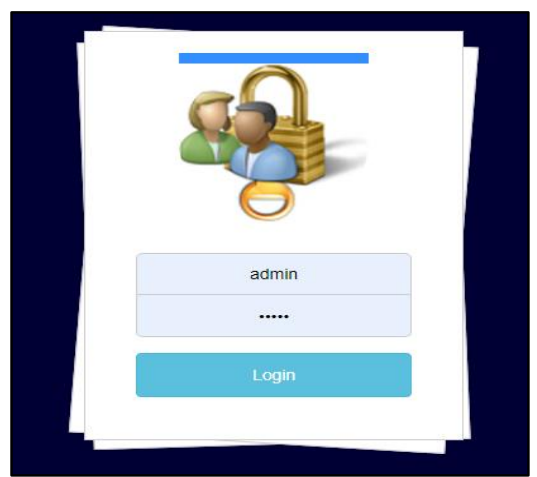

Gambar 8. Tampilan Halaman Login

\section{b. Halaman Menu Utama Sistem}

Halaman menu utama adalah halaman awal yang akan ditampilkan setelah dilakukan login, pada halaman menu utama terdapat menu-menu yang terdapat di sidebar, dan menampilkan dashboard berupa jumlah Data Training dan data testing. Berikut merupakan halaman antarmuka menu utama yang tertuang pada gambar 9 berikut ini. 


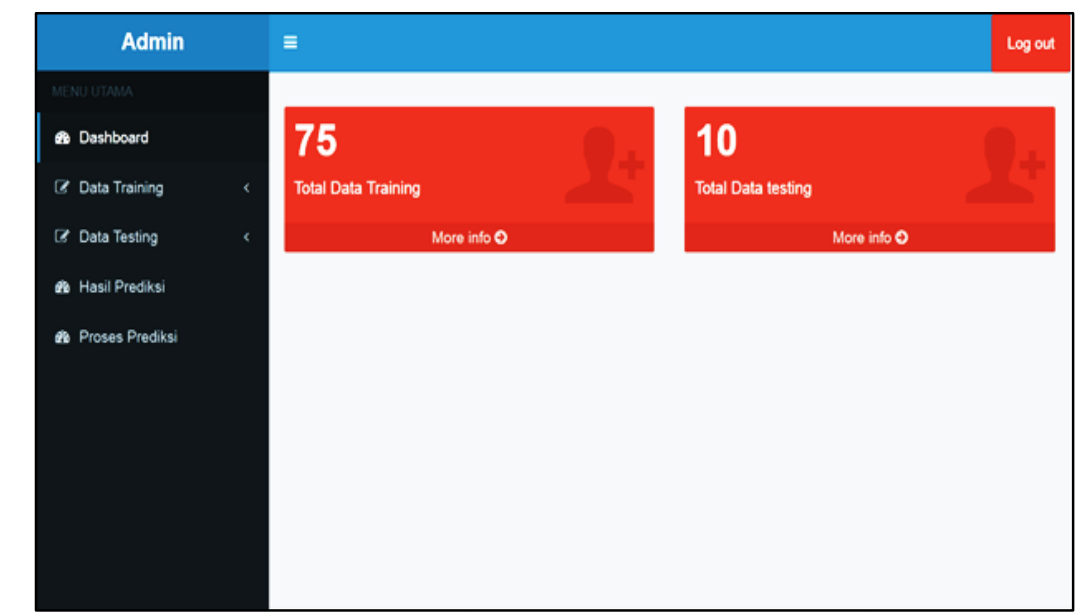

Gambar 9. Tampilan Halaman Menu Utama Sistem (Dashboard)

\section{c. Data Training}

Pada halaman Data Training seperti pada gambar 10 di bawah ini, sistem menampilkan tabel data karyawan sebagai Data Training, sistem bisa mengedit, menghapus, mencari, mengimport, dan menginput Data Training.

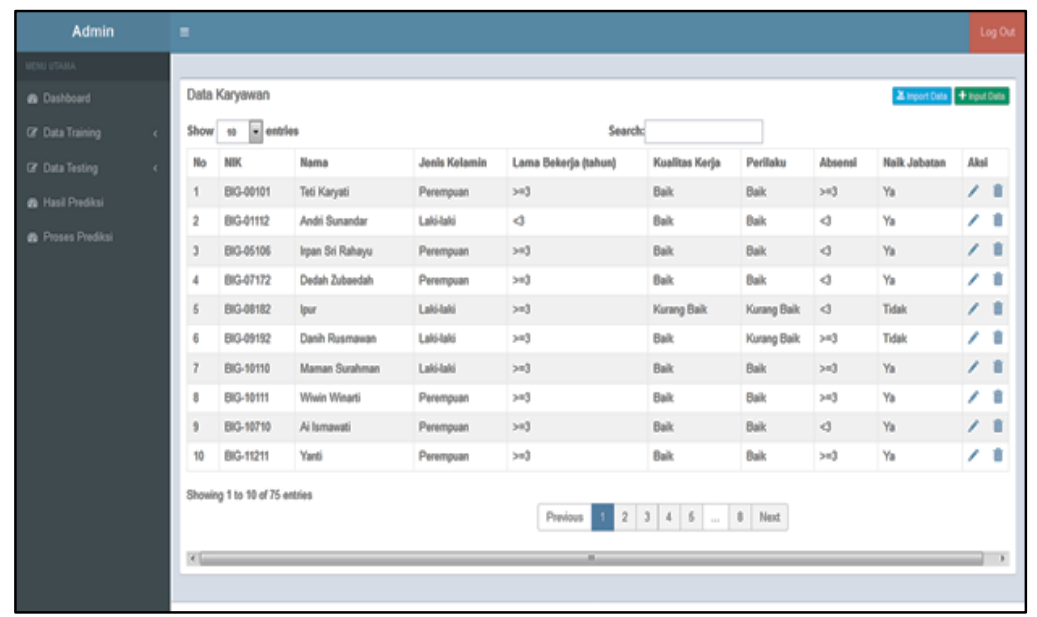

Gambar 10. Tampilan Halaman Data Training

\section{d. Data Testing}

Pada halaman data testing sistem seperti pada gambar 11 di bawah ini menampilkan tabel data karyawan sebagai data testing, sistem bisa mengedit, menghapus, mencari, mengimport, dan menginput data testing. 


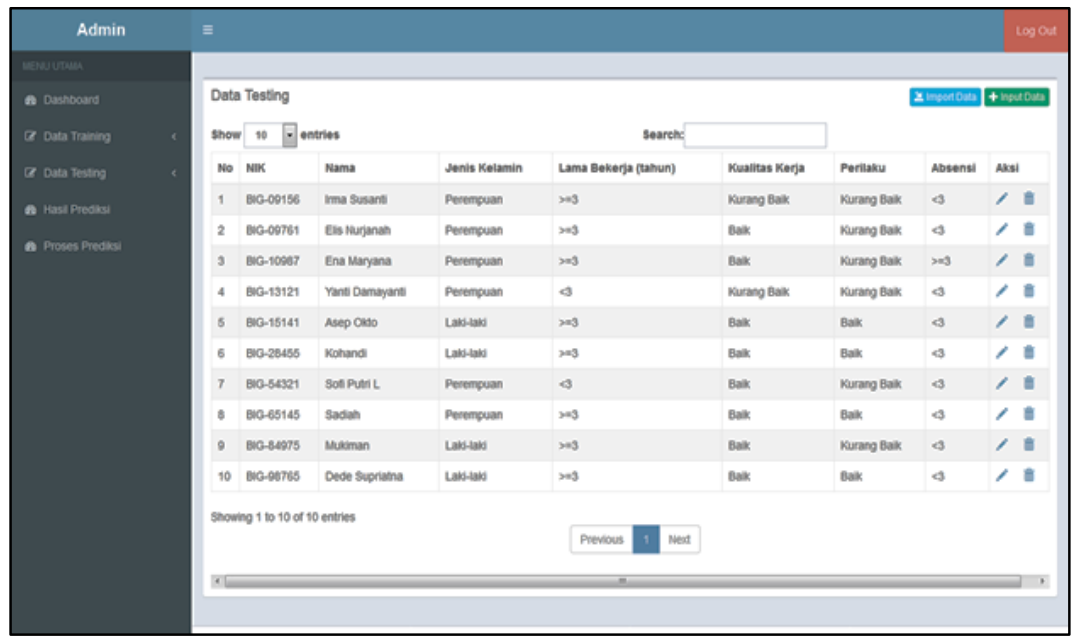

Gambar 11. Tampilan Halaman Data Testing

e. Hasil Prediksi

Pada halaman hasil prediksi seperti pada gambar 12 di bawah ini, sistem menampilkan hasil prediksi dari data testing yang sudah diinput sebelumnya dan detail perhitungannya.

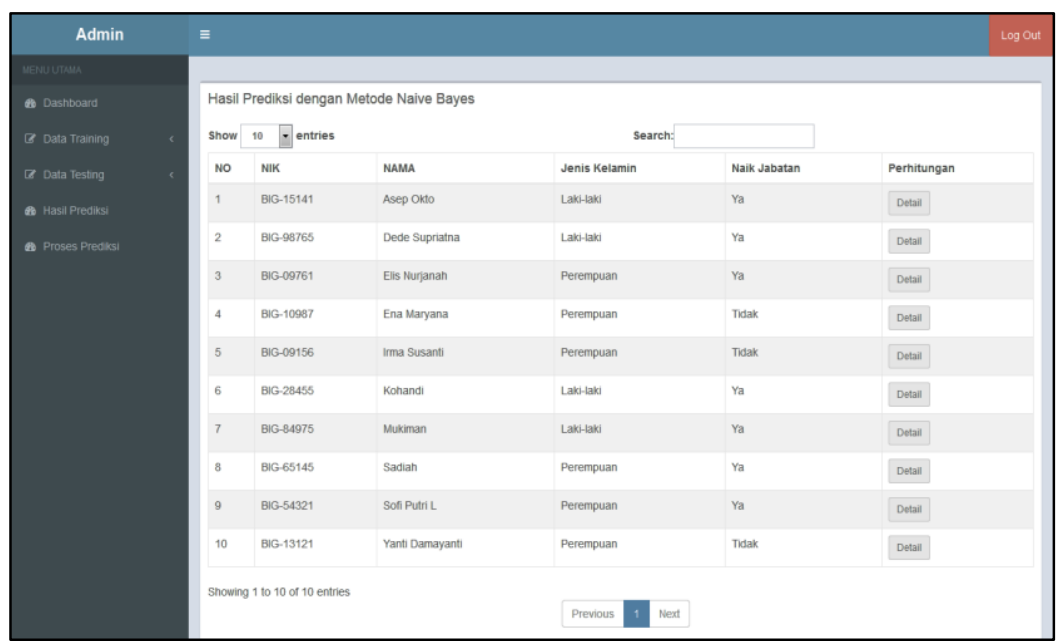

Gambar 12. Tampilan Halaman Hasil Prediksi

\subsection{Pengujian Sistem}

Pengujian sistem merupakan tahap yang paling penting untuk mengetahui apakah sistem yang dibuat berjalan dengan baik atau tidak. Pengujian sistem yang digunakan pada penelitian ini adalah pengujian Black Box Testing. Pengujian Black Box Testing yaitu suatu metode dari perancangan data yang akan diuji berdasarkan atas spesifikasi perangkat lunak yang tersedia. Pada mekanismenya Black Box Testing ini dilakukan untuk menguji fungsi sistem dan operasinya, menguji apakah input dan outputnya sudah sesuai dengan yang diharapkan dan tidak ada kesalahan dalam proses menjalankannya [14]. Berikut merupakan uraian dari scenario pengujian yang dilakukan sebagaimana tertuang pada table 3 di bawah ini.

Tabel 3. Skenario Pengujian

\begin{tabular}{|l|l|l|c|}
\hline No & \multicolumn{1}{|c|}{ Skenario Pengujian } & \multicolumn{1}{c|}{ Yang Diharapkan } & Kesimpulan \\
\hline 1 & $\begin{array}{l}\text { Mengisi } \text { username dan password } \\
\text { dengan benar }\end{array}$ & $\begin{array}{l}\text { Valid dan masuk ke menu } \\
\text { utama }\end{array}$ & Valid \\
\hline
\end{tabular}




\begin{tabular}{|l|l|l|c|}
\hline 2 & $\begin{array}{l}\text { Tambah Data Training, lalu klik } \\
\text { "simpan" }\end{array}$ & $\begin{array}{l}\text { Berhasil dan menampilkan } \\
\text { pesan "data telah } \\
\text { ditambahkan" }\end{array}$ & Valid \\
\hline 3 & $\begin{array}{l}\text { Sistem melakukan proses edit } \\
\text { Data Training }\end{array}$ & $\begin{array}{l}\text { Berhasil dan memunculkan } \\
\text { pesan "data telah diedit" }\end{array}$ & Valid \\
\hline 4 & $\begin{array}{l}\text { Sistem melakukan proses delete } \\
\text { Data Training }\end{array}$ & $\begin{array}{l}\text { Data Training akan otomatis } \\
\text { terhapus }\end{array}$ & Valid \\
\hline 5 & $\begin{array}{l}\text { Tambah data testing (Data yang } \\
\text { diinput lengkap dan benar), lalu } \\
\text { klik "simpan" }\end{array}$ & $\begin{array}{l}\text { Berhasil dan menampilkan } \\
\text { pesan “ } \\
\text { data telah ditambahkan" }\end{array}$ & Valid \\
\hline 6 & Sistem melakukan proses edit & $\begin{array}{l}\text { Berhasil dan memunculkan } \\
\text { pesan "data telah diedit" }\end{array}$ & Valid \\
\hline 7 & $\begin{array}{l}\text { Sistem melakukan proses delete } \\
\text { data testing }\end{array}$ & $\begin{array}{l}\text { Data testing akan otomatis } \\
\text { terhapus }\end{array}$ & Valid \\
\hline 8 & Sistem melakukan proses prediksi & $\begin{array}{l}\text { Sistem berhasil menampilkan } \\
\text { detail perhitungan dan data } \\
\text { hasil prediksi }\end{array}$ & Valid \\
\hline
\end{tabular}

\section{Kesimpulan}

Berdasarkan hasil penelitian dan pembahasan yang berkaitan dengan prediksi kenaikan jabatan karyawan di PT. Busana Indah Global, maka peneliti dapat menyimpulkan bahwa setelah melakukan penguijian pada software RapidMiner, tingkat akurasi yang dihasilkan menggunakan metode Naive Bayes Classifier sebesar 91,67\%, ini menunjukkan bahwa model yang dihasilkan sangat baik. Dan dengan nilai kurva ROC sebesar 0,979 yang berarti model yang dihasilkan semakin baik. Sehingga dapat disimpulkan bahwa metode Naive Bayes Classifier merupakan metode klasifikasi yang direkomendasikan untuk melakukan prediksi kenaikan jabatan karyawan. Dan pengujian aplikasi sistem yang telah dibuat menggunakan Black Box Testing menghasilkan hasil valid. Sehingga dapat disimpulkan bahwa sistem yang telah dibuat mampu diimplementasikan sesuai dengan tujuannya yaitu melakukan analisa prediksi kenaikan jabatan karyawan.

\section{Daftar Pustaka}

[1] A. Muqtadir and I. Purdianto, "Sistem Pendukung Keputusan Kenaikan Jabatan Menggunakan Metode Profile Matching (Studi Kasus di PT. Industri Kemasan Semen Gresik)," Tek. Inform. Univ. PGRI Ronggolawe, 2013.

[2] Anief Rufiyanto, "DATA MINING."

[3] D. Nofriansyah, "Algoritma Data Mining Dan Pengujian."

[4] H. Annur, "Klasifikasi Masyarakat Miskin Menggunakan Metode Naive Bayes," Ilk. J. Ilm., 2018, doi: 10.33096/ilkom.v10i2.303.160-165.

[5] Yusra, D. Olivita, and Y. Vitriani, "Perbandingan Klasifikasi Tugas Akhir Mahasiswa Jurusan Teknik Informatika Menggunakan Metode Naïve Bayes Classifier dan KNearest Neighbor," Sains, Teknol. dan Ind., 2016, doi: 10.1002/mame.201200226.

[6] N. Wijaya, "Penerapan Algoritma Klasifikasi Naive Bayes Untuk Data Status Huni Rumah Bantuan Dana Rehabilitasi Dan Rekonstruksi Pasca Bencana Erupsi Gunung Merapi 2010," 2019.

[7] H. D. Wijaya and S. Dwiasnati, "Implementasi Data Mining dengan Algoritma Naïve Bayes pada Penjualan Obat," J. Inform., 2020, doi: 10.31311/ji.v7i1.6203.

[8] D. Novianti, "Implementasi Algoritma Naïve Bayes Pada Dataset Hepatitis Menggunakan RapidMiner," vol. XXI, 2019. 
[9] D. Gustian, M. Nurhasanah, and M. Arip, "Sistem Pendukung Keputusan Seleksi Penerimaan Karyawan Dengan Metode Analytical Hierarchy Process," J. Komput. Terap., 2019, doi: 10.35143/jkt.v5i2.3336.

[10] Yuli Mardi, "Data Mining: Klasifikasi Menggunakan Algoritma C4.5," Edik Inform.

[11] M. Sabransyah, Y. N. Nasution, and F. D. T. Amijaya, "Aplikasi Metode Naive Bayes dalam Prediksi Risiko Penyakit Jantung,” EKSPONENSIAL, vol. 8, 2017.

[12] M. P. Sudaryono, Statistika Probabilitas - Teori dan Aplkasi. Yogyakarta: CV Andi Offset, 2012.

[13] D. Wahyudi, M. K. A.Haidar Mirza,S.T., and M. K. Merrieayu P.H., "IMPLEMENTASI DATA MINING DENGAN NAIVE BAYES CLASSIFIER UNTUK MENDUKUNG STRATEGI PROMOSI (Studi kasus Universitas Bina Darma Palembang)."

[14] C. K. Sastradipraja, D. Gustian, and S. D. Antadipura, "Perencanaan Strategi Sistem Informasi Penjualan Menggunakan Pendekatan Togaf Adm,” vol. 4, 2019. 